The trends reported by Broderick et al. have continued. During 2006-2014, the incidence of meningococcal disease caused by vaccine-covered serogroups among US military recipients of MCV-4 fell to 0.146 per 100,000 person-years, whereas MPVS-4-related incidence did not change (M.P. Broderick, pers. comm.). Furthermore, through July 2016, the US military has not seen a case from a covered serogroup since 2011 among recipients of MCV-4. Even with these additional data, however, the difference between MCV-4 and MPSV-4 does not achieve statistical significance (M.P. Broderick, pers. comm.).
The author is an employee of a company that manufactures both conjugate and polysaccharide meningococcal vaccines.

\section{Reference}

1. Broderick MP, Phillips C, Faix D. Meningococcal disease in US military personnel before and after adoption of conjugate vaccine. Emerg Infect Dis. 2015;21:377-9. http://dx.doi.org/10.3201/ eid2102.141037

Address for correspondence: Michael Decker, Sanofi Pasteur, Medical Affairs, 1 Discovery Dr, Swiftwater, PA 18370, USA; email: eid@deckerfamily.org

\title{
Correction: Vol. 22, No. 8
}

The name of author Natalie Witek was misspelled in Baylisascaris procyonis-Associated Meningoencephalitis in a Previously Healthy Adult, California, USA (C. Langelier et al.). The article has been corrected online (http://wwwnc. cdc.gov/eid/article/22/8/15-1939_article).

\section{Corrections: Vol. 22, No. 9}

Some descriptions of tickborne transmission of bacteria were unclear in Large-Scale Survey for Tickborne Bacteria, Khammouan Province, Laos (A.J. Taylor al.). The article has been corrected online (http://wwwnc.cdc.gov/eid/ article/22/9/15-1969_article).

A second affiliation for author Martie L. van der Walt was omitted in Treatment Outcomes for Patients with Extensively Drug-Resistant Tuberculosis, KwaZulu-Natal and Eastern Cape Provinces, South Africa (C.L. Kvasnovsky et al.). The article has been corrected online (http://wwwnc.cdc.gov/eid/article/22/9/16-0084_article).

\section{EID Podcast: Nipah Virus Transmission from Bats to Humans Associated with Drinking Traditional Liquor Made from Date Palm Sap, Bangladesh, 2011-2014}

Nipah virus (NiV) is a paramyxovirus, and Pteropus spp. bats are the natural reservoir. From December 2010 through March 2014, hospital-based encephalitis surveillance

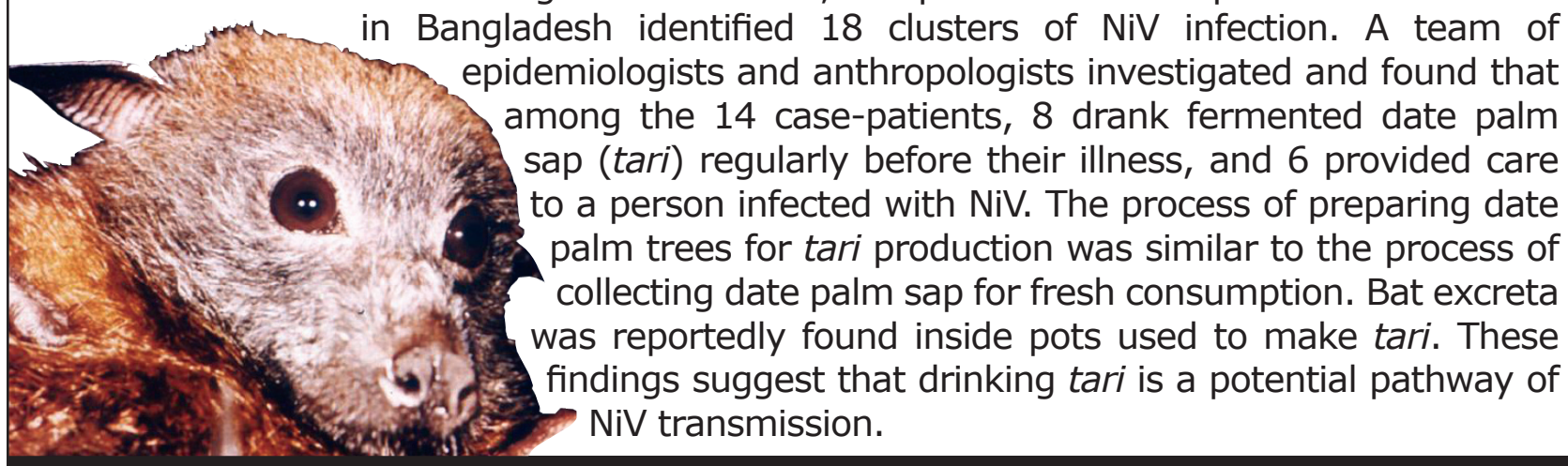

Visit our website to listen: http://www2c.cdc.gov/podcasts/player.asp?f=8642667 